\title{
Urbanidades invisíveis
}

Carlos Fortuna*

https://orcid.org/0000-0002-3102-3710

\begin{abstract}
Mas "embaixo", a partir dos limiares onde cessa a visibilidade, vivem os praticantes ordinários da cidade. Forma elementar dessa experiência, eles são caminhantes, pedestres, Wandersmänner, cujo corpo obedece aos cheios e vazios de um "texto" urbano que escrevem sem poder lê-lo. Michel De Certeau (1994, p. 159).
\end{abstract}

Abertura ou A esperança da sociologia das cidades

Permito-me iniciar, com essa inspiradora referência de De Certeau, essas reflexões sobre aquilo que as cidades planejadas escondem ou não querem ver. A visibilidade tem limiares, além dos quais nada mais se consegue ver. É uma cegueira cognitiva a que estou a referir. Aquela que se revela limitada e curta em função dos critérios usados para captar e ver o que está e deve ser exposto. O lado epistemológico dessa cegueira quero tratá-lo a partir das cidades e daquilo que a formalidade dos seus planos e desenhos não capta, em resultado do que é a ampla discrepância existente entre a cidade concebida e desenhada e a cidade praticada e vivida que aqueles planos e desenhos fazem crescer sem parar.

A questão não é nova. Henri Lefebvre, há exatamente cinquenta anos, abriu um campo crítico de reflexão sobre a condição urbana através do célebre $O$ direito

\footnotetext{
* Universidade de Coimbra, Coimbra, Portugal.
} 
à cidade, e não mais deixou de a abordar em seus escritos. Para o propósito desta abordagem epistemológica da cegueira, o tratamento lefebvriano da representação (Lefebvre, 1980) é o que mais nos interessa. O representado, para Lefebvre, é a marca de uma presença ou existência ausente e, desse modo, presença da cidade e dos espaços urbanos representados no plano arquitetônico e urbanístico, não sendo nem a cidade empiricamente vivida nem os espaços reais e socialmente experimentados que alimentam a reflexão sociológica sobre o urbano. Na linguagem de Fraya Frehse, essa tentativa de revelar e questionar o que não foi empiricamente experimentado é o mister corrente da sociologia e, mais que isso, constitui mesmo os "lugares da esperança da sociologia” (Frehse, 2017, p. 44).

Que esperança da sociologia é esta? É a de valorizar e tornar visíveis as práticas dos "praticantes ordinários da cidade" de Certeau, que é o mesmo que colocar a cidade dentro dos planos formais do seu desenvolvimento urbanístico. É essa tarefa monumental que continua a abrir o campo da reflexão sociológica sobre a cidade, mesmo que não seja uma questão nova. Nessas linhas pretendo, eu também, modestamente, entregar-me a essa incontornável esperança da sociologia.

Essa não será apenas uma esperança de melhoria e aprofundamento da visão da sociologia sobre a cidade, os seus tempos e os seus espaços, já que esse afinamento epistemológico diz respeito também à generalidade das ciências sociais e das humanidades. É uma esperança teórica e política e, nesse sentido, uma esperança universal de diálogo e ajustamento dentro e entre visões disciplinares distintas que abrange, portanto, as leituras particularísticas da cidade e do urbano. Entre essas visões, pressinto a necessidade primordial de desnacionalizar as leituras correntes sobre a cidade e o urbano e superar os constrangimentos impostos pela sua interpretação nacional. É a complexidade das espacialidades e das temporalidades de um urbano que se move de acordo com geografias e ritmos insuspeitos até há pouco, que condiciona as práticas sociais que têm lugar nas cidades e que configuram aquela esperança de um entendimento interpretativo transversal e globalizante da cidade. À sua maneira, todas e cada uma das cidades de hoje pouco mais são do que experiências políticas e manifestações socioculturais em torno de uma tendência urbana geral que supera a soma das suas partes, embora se possa expressar e ser compartilhada de forma singular. É nessa visão que este texto procurar dialogar com o tópico geral deste dossiê que deseja "pensar" a cidade, os seus "tempos" e os seus "espaços", ... no Brasil ou fora dele.

No recente Construir e habitar, Richard Sennett (2018), a partir de uma dupla condição de urbanista e sociólogo praticante, coloca-se perante o hiato existente entre fazer e viver a cidade. A "esperança” de Sennett é a de contribuir para uma cidade entendida como sistema aberto, em que valores diversos de sociedade, cultura, religião, etnia e ambiente coabitem em mútuo respeito. Essa é a sua pretendida open 
city, ainda por construir. A primeira interrogação que se coloca é a de saber por que razão, em pleno século XXI, de posse de tanto e tão variado saber sobre o que é uma cidade "aberta" e justa, continuamos sem conseguir construí-la. Susan Fainstein interrogou-se sobre isso e concluiu que a cidade justa continua sendo uma miragem por motivos políticos e ausência de democracia nas decisões (Fainstein, 2010). Sennett oferece uma hipótese mais complexa e fixa-se na incoerência dos planos de cidade, a qual decorre da ausência e desconsideração dos modos informais de habitar e viver a cidade, no juízo tecnocrático dos seus "fazedores” profissionais: arquitetos, urbanistas, planejadores urbanos, engenheiros.

Na minha interpretação, a centralidade dada à dimensão dos espaços da cidade faz perder de vista os lugares de que a cidade é feita. Os lugares são geografias sociais próprias, que assumem formas diversas e que, principalmente, são revestidas por significados, valores e linguagens atribuídos por quem e como as apropria e usa. Esses lugares da cidade são espacialidades sensíveis que, retornando a Lefebvre, alojam teatralizações inconscientes e espontâneas, como sejam "ligações e obstáculos, jogos de reflexos, de devoluções, de espelhos, de ecos" (Lefebvre, 1991, p. 210). Todos esses são elementos intangíveis, espontâneos, irrepetíveis e inscritos na informalidade do cotidiano da cidade. Numa palavra, elementos epistemologicamente tornados "invisíveis". Como inscrevê-los na formalidade institucional do plano e das políticas da regulação da cidade? Se estão além "dos limiares da visibilidade” cognitiva, não se deixam captar e nem a sua energia pode ser planejada como integrante da cidade futura. Mas, como anunciado, se considero ser cognitiva a cegueira que desejo abordar aqui, a solução estará em procurar trazer alguma subterraneidade urbana até o plano da visibilidade, e não o contrário, ou seja, insistir em desenhar mais e mais cidade sem gente dentro e invisibilizada. A esperança sociológica deste texto resume-se ao modesto esforço de contribuir para que possamos ter mais cidade transparente e menos cegueira urbanística e arquitetônica.

\section{O que a cidade esconde e mostra ao mesmo tempo}

No decurso fílmico de Die Straße, o filme mudo produzido em 1923 por Karl Grune ${ }^{1}$, um sujeito de classe média, de meia idade e ar sisudo, sai intempestivamente de casa, atraído por um imaginário de aventura, incluindo a aventura sexual, que a rua promete através do movimento das sombras dos passantes que a janela entreaberta deixa projetar no teto da sala. Uma vez na rua, o sujeito aproxima-se, insinuante, da atraente jovem com quem trocara um breve e malicioso olhar. Nesse instante, a jovem

1. Disponível em <www.youtube.com/watch?v=f-s_aQkkt24>; acesso em 28.1.2018. 
transfigura-se em ameaçadora caveira e, de um momento para o outro, o ambiente urbano que prometera sensualidade e prazer revela-se aterrador e causa pânico. $\mathrm{O}$ homem refreia os seus instintos e retira-se, cedendo perante a surpreendente realidade plástica e distópica que o momento ostenta.

Desde os seus primórdios, o uso social das tecnologias da imagem, a fotografia ou o filme, tratou de sinalizar o que era marca indelével da moderna condição urbana. Os cenários de sedução, medo e conflitualidade, por um lado, assim como as descrições dos avanços prodigiosos da tecnologia urbanizada, por outro, eram testemunhados com avidez por plateias interessadas na narrativa que tudo mostrava. Os relatos mais sombrios da precariedade e da miséria urbanas eram, grosso modo, remetidos à literatura e ao teatro.

As primeiras cenas do filme de Karl Grune mostram o chamado da cidade - que impele o sujeito para a rua -, ao mesmo tempo que desafiam a pensar que algo de temeroso existe para lá do imediatamente representado na cena urbana. Seja através do tratamento de subjetividades e sentimentos pessoais ou de paisagens e comportamentos inusitados, ou da própria materialidade das coisas, a cidade é percebida como cenário em contínua mudança, sujeita às mais variadas oscilações e dispositivos que tanto revelam como encobrem (Pechman, 2014).

Hoje, em tempos de manifesta iconocracia, impera o reino da superficialização do revelado, e, mesmo quando as imagens mergulham no domínio mais reservado e íntimo da condição humana, elas acabam por o banalizar à força de tanto o trazer à vista. A rua como expressão material da superfície urbana não expõe todos os sinais que conduzem e controlam os seus modos de uso e apropriação, pelo que são frequentes os seus "contra-usos" (Leite, 2004). Uma compreensão integral da rua requer uma reflexão aturada que as ciências sociais e as humanidades têm explorado para tornar acessível o que permanece escondido, ou no máximo entendido na sua superficialidade, ou seja, no plano de uma apreciação distraída e errônea².

No domínio das artes, por paradoxal que possa parecer, encontramos múltiplas formas de revelar escondendo, dimensões insuspeitas da materialidade das coisas urbanas e de visões outras do social. Por exemplo, Christo Javacheff e Jeanne Claude cobriram lugares singulares e construções únicas da arquitetura monumental ocidental, como o Reichstag berlinense ou a Pont Neuf em Paris, que mostraram a

2. Um outro nível de revelação do invisível urbano que não seguirei aqui é a descida às profundezas subterrâneas da cidade. É esse o intersticial relato que Bruno Latour e Émilie Hermant oferecem de Paris vista debaixo do chão. É ali, nos subterrâneos não visíveis e escondidos da cidade, que se articula o grande complexo de infraestruturas, mecanismos e equipamentos que, segundo os autores, é preciso conhecer, "se queremos compreender o que, um dia após outro, assegura o conjunto da vida urbana" (Latour e Hemant, 1998, p. 90). 
milhares de turistas apreciadores desta técnica do embrulho ${ }^{3}$. Em 1952, no campo da música, John Cage tocou a sua célebre e surpreendente composição 4' 33' e inverteu desse modo o sentido da produção e da apreciação estética da música. Em Portugal, o cineasta João César Monteiro apresentou, no ano de 2000, uma "Branca de Neve" que ele conduz ao paroxismo da performance fílmica, ao recobrir e não deixar ver as imagens, e ao mostrar apenas as cenas da sonoridade dos diálogos dos invisibilizados atores.

A atual tirania da visualidade permite abrir à nossa exploração o que chamarei de domínio de negatividade, inspirado na abordagem da ética social do filósofo Avishai Margali (1996). A ideia de negatividade refere-se à tomada de consciência política de que a aceitação indiscutida da normatividade e das regras instituídas de funcionamento e controle da vida social - e, por extensão, da vida urbana - não decorre da experiência empírica de justiça social, mas da percepção das graves expressões de injustiça. Do mesmo modo, ela também não resulta da prática de distribuição equitativa de recursos, mas das mais acentuadas expressões de desigualdade no acesso a esses recursos, como não decorre da felicidade e bem-estar, mas do sofrimento e da humilhação (Margali, 1996).

Assim, apelar a uma política de negatividade da cidade é insistir numa visão da cidade a partir do outro lado. Que outro lado? O lado subalternizado e desclassificado das periferias socioculturais e espaciais que o poder dos centros urbanos estipula e esconde. Tal remete ao que Boaventura de Sousa Santos designa por "sociologia das ausências", cujo objetivo primeiro é "revelar a diversidade e multiplicidade práticas sociais", mormente as práticas sociais subalternizadas, de forma a se alcançar "uma versão ampla de realismo, que inclui as realidades ausentes por via do silenciamento, da supressão e da marginalização, isto é, as realidades que são ativamente produzidas como não existentes" (Santos, 2010, p. 107). As narrativas identitárias que os sujeitos dessas periferias urbanas produzem, no confronto com os seus Outros antropológicos, juntam-se a outras descrições, em resultado do que, no seu conjunto, as narrativas disponíveis podem gerar dispositivos de qualificação da própria condição de vida de tais sujeitos da realidade urbana e alterar a sua própria ação. Esse envolvimento pessoal ativo - emplotment, como diria Paul Ricoeur (Ricoeur, 1991) - na imagem

3. Christo Javacheff (1935-) e Jeanne-Claude (1935-2009) são um casal de artistas dedicados à arte ambiental, com inúmeros e aclamados trabalhos de recriação das paisagens urbanas, por todo o mundo. A técnica que usavam então era baseada no "embrulho" de edifícios e equipamentos urbanos, o que tornava a sua arte profundamente efêmera. Os artistas vangloriavam-se com o fato de as suas criações artísticas não terem existência além do tempo da sua exposição (dispónível em $<$ http://christojeanneclaude.net/>; acesso em 28.7.2018). Nesta sequência, veja-se a problematização da relação dos humanos com os materiais da cidade oferecida recentemente por Amin e Thrift (2017). 
de si próprio constitui, a todos os títulos, uma ação de autocapacitação de sujeitos excluídos e desapossados, ação com enorme potencial para a reconstrução da consciência negativa da sua condição.

Não são apenas as políticas dirigidas de cima para baixo que recorrem ao expediente de invisibilização. Por um lado, a invisibilização dos espaços pode ser causada, indiretamente, pelo atual aceleracionismo, que pressupõe a circulação rápida dos cidadãos comuns pelos territórios e espaços públicos do centro, e induz à invisibilização desses territórios submetidos a rápidas idas e vindas que ou não favorecem os contatos entre desconhecidos ou tornam-nos espúrios e socialmente inconsequentes. Por outro lado, são inúmeros os indivíduos e grupos que tornam estrategicamente invisível a sua existência social a coberto da informalidade cotidiana da cidade, e conseguem, desse modo, escapar ao controle social e policial (Aubert e Haroche, 2011). Esse recurso é usado tanto por cidadãos vulneráveis, comerciantes pobres ou imigrantes indocumentados, como é também estratagema de fuga a encargos fiscais e ação clandestina. Nessa sequência, são vários os estudos que mostram como a informalidade urbana constitui um ambiente propício a formas diversas de insurgência e contestação política contando com o apoio discreto de vizinhos pobres (Roy, 2009; Simone, 2011).

\section{Em busca da negatividade urbana}

O encontro e a abertura sociocultural, racial e religiosa da cidade são uma pré-condição para a concretização de uma idealizada open city. Não basta, em meu entender, a copresença física dos corpos e o encontro ou a conversa ocasional em espaço público. É importante pensar sobre o conteúdo dessa conversa, o que nos transporta para o domínio da educação, da expressão linguística e da disposição para a ação comunicativa das pessoas. Esse encontro não é do estilo da abordagem defraudada que o sujeito sisudo do filme de Karl Grune forçava com a jovem transeunte na rua da cidade. Essa era uma ação unipessoal, desigual e codificada a que a jovem se furtou, reconfigurando-se ela própria em personagem agressiva e ameaçadora. O encontro sociocultural aberto a que me refiro [trans] decorre supostamente em ambiente público das ruas e praças das cidades e megacidades - "a rua é a morada do coletivo", dizia Walter Benjamin (2009, p. 958) - e expressa-se através da interação de pessoas de condição social equivalente caucionada pelo espaço partilhado. Uma oralidade de tipo convivial, quase desaparecida das relações do cotidiano, permite uma comunicação interpessoal que apenas o imaginário do medo evita que se possa tornar expressão banal do cotidiano.

Será possível planejar ou preservar essa cidade através da negatividade e da autocapacitação dos mais frágeis, e é possível incluir no plano de cidade a informalidade 
do cotidiano social? Abordo a questão de um ângulo especial, dizendo que o que parece claro é que os "fazedores" de cidades - arquitetos, urbanistas, planejadores urbanos, engenheiros e decisores políticos - podem evitar continuar a trabalhar no sentido do fechamento, da exclusão e da marginalização socioespacial. Em vez disso, quero admitir que possam adotar uma atitude reflexiva e crítica, e atuar em busca de práticas alternativas que vão ao encontro do que a formalidade dos seus planos de cidade continuam a invisibilizar, por cegueira cognitiva ${ }^{4}$.

São várias e de natureza diversa as dificuldades para que essa esperança da sociologia urbana possa concretizar-se. A primeira dificuldade é o fato de, como se deixou já implícito (Tonkiss, 2013, p. 96), a informalidade manter uma relação complexa com a (in)visibilidade. Na economia urbana, a informalidade remete diretamente, embora sem fundamento que permita generalizações, ao ilícito e ao clandestino, criando à partida um obstáculo à sua aceitação. No plano da política, o informal da vida urbana surge muitas vezes conectado com as máfias organizadas em redor de redes de distribuição comercial ou domínio de pontos de venda ("shoppings populares”) e atuando por ação compulsiva, extorsão e parasitismo empresarial.

O que mais alimenta essa informalidade e poderá estar ao alcance de uma nova atitude dos "fazedores" de cidade é, primeiro, a incontrolável densificação das periferias da cidade e, em segundo lugar, o ritmo acelerado do crescimento da população urbana. A densificação das margens da cidade tem um modo especial de funcionamento relacionado diretamente com o uso do espaço e a infraestruturação dos acessos ao centro da cidade. Neste atual momento da história urbana, a solução para esse problema não parece ser - nem ninguém a considera como tal - a de eliminar as zonas suburbanizadas e as periferias, mas antes a de as dotar de condições e equipamentos materiais eficientes, assim como assegurar os meios de transporte e de ligação com o centro urbano.

Quanto à questão da veloz concentração urbana, ela está diretamente relacionada com os desequilíbrios estruturais e políticos que lesam a condição de vida e os direitos da grande parte da população, desde logo os mais vulneráveis e os recém-chegados. A velocidade desse crescimento - medido de acordo com o número de pessoas que

4. Por vezes, a vontade de não querer ver a absoluta precariedade e o total desrespeito pela dignidade humana conduz a que as autoridades não atuem na solução de graves problemas nas periferias das cidades. O antropólogo paquistanês Arjun Appadurai assinala como nos bairros pobres de muitas megacidades a falta absoluta de infraestruturas conduz ao que designa "política de merda" ("shit politics"), para significar a necessidade de urinar ou defecar em lugares públicos, nem sempre resguardados (Appadurai, 2002, p. 37). Em informação pessoal, a socióloga Sujata Patel deu-me conta do conhecimento geral sobre as horas de maior ocorrência dos estupros de mulheres nas periferias da cidade indiana de Pune serem as horas matinais, quando elas têm de satisfazer as necessidades fisiológicas em campo aberto, dada a ausência de banheiro no interior das casas. 
chegam à cidade a cada hora - é mais acentuada nas megacidades pós-coloniais da África e da Ásia e sobrepuja largamente a cadência da vida vivida nas suas congêneres do Norte global (Fortuna, 2016). Noutro lugar mostrei que o ritmo desigual desse crescimento revela a existência de um metropolitanismo tripartido, coincidente com as três gerações de metrópoles - as "velhas", as "novas" e as "novíssimas” (Idem). São as últimas e mais recentes, entre as quais se contam cidades como Lagos, Daca, Mumbai ou Jacarta, as que crescem ao ritmo alucinante de entre 39 a 50 pessoas em média, a cada hora que passa (Idem). São manifestas as condições desiguais de sustentabilidade sociocultural (equipamentos sociais), política (universalidade de direitos) e infraestrutural (habitação, saúde e transportes) que enfrentam essas novíssimas metrópoles, em consequência de políticas liberais de investimento seletivo e restritivo e da inexistência, omissão ou retração de políticas sociais estatais que conduz a zonas de absoluta destituição, a que Loïc Wacquant chama de "hiperguetos" (Wacquant, 2008). Poderemos esperar dos "fazedores" de cidades uma ação que possa contrariar essa perniciosa e desigual velocidade da metropolização do mundo? A resposta é técnica e política. Pela qualidade e a durabilidade dos equipamentos, a capacidade residencial e as condições do seu uso social, podemos esperar que sejam os técnicos a encontrar as soluções mais adequadas. Pela erradicação das origens do constante êxodo para a cidade - fomes, guerras, desertificação e desastres ambientais - e a sua densificação devem responder os políticos e decisores.

\section{A normalidade urbana}

Para reconfigurar esta análise é preciso trazer a ideia de negatividade a outras condições gerais da urbanidade contemporânea, e buscar nela as alternativas possíveis para contrariar os efeitos da aceleração do tempo e da cenarização dos espaços da cidade sobre as condições de vida. Ana Fernandes, num curto e instigante texto (Fernandes, 2006), aborda essa questão do lado do que chama o "rompimento" da cidade com a cadência humana do tempo e da "promessa" de se poder pensar o espaço e a materialidade da cidade de acordo com os melhores anseios e expectativas dos cidadãos.

Está em causa resguardar a biografia sociopolítica dos lugares, das ruas e praças da cidade, conferindo-lhes uma relevância socio-histórica e cultural que as liberte da análise imediatista de projetos de modernização e promoção/competição internacional das cidades, em que é determinante o papel de arquitetos, planejadores e urbanistas. Ações de gentrificação e de turistificação dos centros das cidades, ao lado da construção desenfreada de condomínios fechados e outros enclaves urbanos, estão a distorcer a ecologia da cidade, sob o lema da modernização e da segurança, ou do 
"limpo e seguro" (Minton, 2009). É muito duvidosa a utilidade social retirada da inclusão das cidades nos esquemas comparativos dos rankings internacionais, para os quais esses processos de modernização são essenciais ao darem por garantidas as infraestruturas urbanas, como sistemas de transportes, de fornecimento de energia, ou redes de hotéis, de consumo e de outros serviços. O hardware urbano só tem sentido se as cidades investirem no seu software, que é a diversidade estrutural e funcional dos espaços públicos das cidades e dos seus bairros e periferias. A meu ver, esses outros espaços introduzem um salutar efeito de diversidade cultural que escapa à lógica da comparação internacional, mas é central para o chamado espírito dos lugares. Como sugere Massimo Cacciari (2010), a noção clássica de cidade compacta e total está a recuar perante o reconhecimento de "cidades-território", ou seja, perante a afirmação de parcelas e fragmentos de cidade suportados por uma "geografia de acontecimentos" e uma cultura do lugar que nem sempre integram os planos de ação urbanística e administrativa. Um olhar mais próximo a essas parcelas da cidade esclarece por que o discurso urbano está a passar por grande convulsão com o surgimento de noções como cidade-território, pós-cidade, ou $U r$-distritos, que assinalam modos emergentes de relacionamento dos sujeitos com os espaços urbanos.

Nesse particular, Sharon Zukin fala de uma cidade autêntica em risco de "perder a alma" por via da muito moderna "cultura do cappuccino" (Zukin, 2010). Por seu lado, Ray Oldenburg valoriza a preservação e o encontro dos "bons e belos lugares" de lazer e consumo da cidade (Oldenburg, 1989). Lyn Lofland sublinha o sentimento de conforto e reconhecimento contido no território "paroquial" situado algures entre o público e o privado da cidade (Lofland, 1998). Não se trata apenas de ensaiar uma nova retórica em defesa de velhas espacialidades e lugares, porque todas as propostas se estribam em avaliação séria dos limites da modernização neoliberal das cidades, procurando, pela política de negatividade, denunciar os seus efeitos e promover alternativas.

Essas possibilidades discursivas novas não alteram a hegemonia dos estudos urbanos ocidentais, com a versão norte-americana à cabeça, seguida da influência britânica, cujos limites são sobejamente conhecidos por conduzirem a um entendimento "inapropriado" do fenômeno urbano global (Watson, 2006).

Retomemos Richard Sennett e a sua inquietação acerca do possível desenho de uma cidade capaz de incorporar a informalidade prática do dia a dia. O grande objetivo éo respeito pelas várias modalidades de relacionamento das pessoas umas com as outras e com os espaços e os seus diversos modos de apropriação, uso e contra-uso. Uma dose variável de informalidade nas relações sociais, econômicas e comerciais está presente como traço profundo da vida urbana tanto nas cidades do mundo em desenvolvimento, como nas cidades dos países do Norte global. Em muitos casos, a 
conservação dessa informalidade resulta do afastamento dos contextos cerimoniais do poder, o mesmo é dizer situações de não-poder. Noutros casos, a sua manutenção resulta da inoperância ou mesmo ausência das políticas estatais, substituídas por políticas do possível e por "expedientes" individuais ou de grupo, mas também por assinalável espírito de solidariedade entre vizinhos.

Esses ambientes e territórios onde grassam alternativas à formalidade da lei e da tradição não são ambientes ou territórios de caos, ainda que sejam variados os relatos de insegurança e violência que por vezes suportam. São ambientes ajustados ao funcionamento de espaços comuns, de economias locais desestruturadas, de transportes ineficientes e de vidas familiares tumultuosas. São imagens invertidas do que sucede nas cidades sobreplanejadas, como sejam Singapura ou Abu Dhabi, entre muitas outras, em que é manifesta a pesada regulação administrativa, estatal e policial, com as suas extensóes ao campo do urbanismo e da atividade econômica. Ao contrário dessa regulação formal da urbanidade, em cidades "normais"s do Sul ou do Norte globais, muitas dessas lógicas surgem articuladas com regras comuns ditadas pela banalidade dos acontecimentos de cotidianos pobres. Seja no que respeita à flexível residência, à multifuncionalidade dos edifícios consoante seja dia ou noite, à atividade comercial e à enorme criatividade, aos transportes caros e raros, ou aos modos de vestir, de comer, de comunicar, o formal e o informal encontram-se lado a lado e repartem entre si, recombinando-os, os procedimentos e as escolhas das pessoas que circulam nas sempre repletas ruas e praças dessas cidades "normais". Com essa variedade de situações e práticas, o tecido urbano converte-se em heterotopia, com os seus múltiplos significados e também as suas múltiplas atividades, desde brincadeiras e divertimentos até o ato simples de estar parado ou às práticas de consumo e de negócios correntes.

$\mathrm{Na}$ urbanidade "porosa" que resulta dessa combinação de estilos e comportamentos formais e informais, a fazer reverberar o retrato fenomenológico que Walter Benjamin e Asja Lacis (1978, p. 166) oferecem da complexa cidade de Nápoles, desenvolvem-se inúmeras práticas de criatividade comercial, regidas por lógicas de sobrevivência e de enfrentamento da carência material. Associadas ao fato de os seus executantes serem, em geral, muito jovens, essa criatividade periférica escapa ou é deliberadamente ignorada pelas reflexões hegemônicas da criatividade urbana, contidas em manuais e discussões acadêmicas acerca das cidades inteligentes e criativas que valorizam a ação de quadros técnicos que se movem no campo da

5. Recorro ao conceito de "cidade normal", por vezes também enunciado como "cidade ordinária", avançado por reconhecidos analistas do universo urbano pós-colonial. Sobre os usos dessas formulações vejam-se, por exemplo, Amin e Graham (1997), Bishop, Phillips e Yeo (2003), Robinson (2006) e Hall (2012). 
moderna tecnologia e da comunicação moderna (Florida, 2002; Carta, 2007; Towsend, 2014) $)^{6}$.

Deyan Sudjic (2017) justifica a permanência dessa criatividade urbana de periferia por ela prometer trazer os pobres à condição de menos pobres. Apesar de se tratar de pura e infinita precariedade, é preferível, de acordo com Sudjic, vender brinquedos feitos na China na rua do que procurar viver da subsistência agrícola no Sudão do Sul (Sudjic, 2017). As situações são incomensuráveis, mas a alegoria serve para mostrar a total falta de expectativas de vida fora das cidades. Talvez isso se deva a uma capacidade de apropriação do espaço urbano que é manifestamente mais "autônoma” do que qualquer tentativa semelhante em contextos não-urbanos. $\mathrm{Na}$ cidade, é possível ocupar física e simbolicamente diversos espaços e curto-circuitar as políticas de regulação estatal através da informalidade e da liberdade dos seus usos. É um exercício de refundação prática dos espaços, feita de acordo com as necessidades das pessoas e não com os objetivos originais e as lógicas dos planos dos arquitetos e urbanistas. Mesmo quando as atividades que ali decorrem têm uma natureza igual às atividades alojadas em lugares semelhantes do centro consolidado da cidade engraxates, biscateiros, recolectores de cartão ou vendedores de água imprópria, venda de todos os tipos de bens lícitos e ilícitos -, a diferença está na autonomia pessoal para refundar os seus significados, alterando também a qualidade física e as configurações sociais do entorno.

Essa cidade informal tem uma lógica espacial própria e não surpreende o seu aproveitamento por classes médias e médias baixas, que concretizam estratagemas menos lícitos ligados à propriedade privada com fins de residência própria ou de especulação.

Essa criatividade alternativa é um ativo a ter em conta na justa representação da open city, exatamente como é a presença física das pessoas na rua normal das cidades "normais". Apesar da recatada intercomunicação das pessoas entre si, aqui os corpos se cruzam, tocam-se, relacionam-se numa colorida e desconcertante dinâmica que faz lembrar o bailado urbano que Jane Jacobs (2000) tanto admirava. Ao mesmo tempo, essa copresença em espaço público supera, pelo número dos seus executantes e a sua maior amplitude espacial, o imaginário de Jacobs acerca dos sidewalks da sua querida Hudson Street (Jacobs, 2000, pp. 39-65). Na ausência de planejamento dessa plural copresença que tipifica muitas áreas urbanas de países em desenvolvimento, as regras de convivência pública são tácitas, o encontro com

6. Jeremy Seabrook, um jornalista britânico engagé, oferece inquietantes relatos dessa luta pela sobrevivência ensaiada diariamente por jovens pobres em grandes metrópoles de países em desenvolvimento (Seabrook, 1996, 2007). 
a diversidade é assumido com facilidade e a ética da urbanidade experimenta-se e flui sem esforço.

\section{Limitar o aceleracionismo urbano}

Muitos planos de cidade não conseguem inscrever o significado dessas interações das pessoas com os espaços desenhados. É por isso que perguntar sobre se se pode planejar a informalidade da vida urbana tem por detrás um não-dito que é o convite a desaprender a cidade formal, juntando-lhe os significados próprios dos fragmentos não convencionais da urbanidade. Parto do princípio de que esses fragmentos só podem ser detectados no percurso lento pela cidade. O aceleracionismo atual convida não ao conhecimento dos lugares que fazem a cidade no seu todo, mas antes à sua incompreensão. Essa cidade veloz clama por autopistas e outras vias rápidas que facilitam chegar num instante a todos os pontos ou atravessá-la de um lado ao outro sem parar. A velocidade distrai e torna as paisagens sociais da cidade invisíveis. Em clara contravenção com isso, o arqueólogo e antropólogo francês André Leroi-Gourhan escreveu um dia que a cultura humana começa pelos pés e pelo caminhar, no que teria o acordo do "homem lento" de Milton Santos (Leroi-Gourhan, 1964). Caminhar na cidade de hoje é um anacronismo, quando as cidades são desenhadas para a rápida deslocação dos corpos sempre em direção a um ponto pré-determinado. Caminhar e parar, ao invés, são modos de penetrar lentamente o interior dos lugares onde se forjam criativas aproximações e interações sociais (Fortuna, 2018). As cidades modernas que favorecem o cidadão automobilizado preocupam-se muito pouco com esses atos imprevistos de parar, sentar-se ou andar de bicicleta. Parado, o sujeito é vulnerável; para sentar-se precisa pagar, nas esplanadas privadas que invadem o espaço público; usar a bicicleta é correr risco de atropelamento.

As coisas estão a mudar devagar e, por certo, pela iniciativa e insistência tenaz de alguns "fazedores" progressistas de cidade. O campo das ciclovias e da pedonalização de ruas comerciais nos centros das cidades é talvez o que tem obtido mais alargados consensos urbanísticos e políticos quanto ao rearranjo "ambiental" dos espaços urbanos ${ }^{7}$.

7. Um breve relance por programas de circulação urbana de pedestres e ciclistas mostra uma enorme adesão por todo o mundo. No que respeita, em particular, à situação de muitas cidades da América Latina, encontram-se alguns programas com inventivas designações, tratando assim de buscar alguma informalidade, a começar pela intervenção no conhecido "Minhocão" de São Paulo, que é um dos raros projetos construídos em altura, seguido do programa "En los zapatos del peatón” de Medellin, o "Pasos e Pedales" na Cidade da Guatemala, o "Ciclorecreovias" em Santiago do Chile ou o "Muévete en Bici" da Cidade de México. Na sua generalidade, esses programas encerram o tráfego de automóvel durante o fim de semana ou ao domingo, para permitir o uso não-motorizado do espaço. Para uma visão geral 
O High Line Park novaiorquino é certamente uma das grandes exceções à impiedosa marginalização do pedestre e do seu ritmo lento. Elizabeth Diller, arquiteta responsável pela nova passagem elevada para pedestres da baixa de Manhattan, que reconverteu um trajeto ferroviário desativado, em que, todavia, os ciclistas não são autorizados, elogia as qualidades do projeto afirmando que

[...] lá não se pode fazer muita coisa, exceto sentar e andar [...] podemos andar continuamente dois quilômetros e meio sem parar. [...] Dali, as pessoas veem coisas não oficiais, que não era suposto verem. Chaminés, lados de edifícios, parques de estacionamento, aquilo que não é o postal típico de Nova Iorque. São segredos, às vezes parece que é o subconsciente de Nova Iorque que está lá (Diller, 2018, p. 6).

A virtude social da lentidão reside em permitir aos sujeitos demorarem-se na negatividade do social urbano que a velocidade suprime. Na lentidão da caminhada é possível ver a cidade do avesso, ver as "coisas não oficiais [...] que não era suposto ver", como explica a arquiteta entrevistada. O seu discurso é otimista porque oferece e qualifica o presente urbano, e projeta um futuro a partir do lado imprevisto e informal da grande cidade. $\mathrm{O}$ aceleracionismo moderno não autoriza pensar os lugares nem o "espírito" de convivência e solidariedade que os envolve. São precisos espaços que contrariem a velocidade do cotidiano urbano e que, assim, evitem que agravemos os tempos de perda de memória e de esperança que nos inícios a cidade tanto prometeu.

Esse futuro será um futuro de cidades complexas, de espaços urbanos e práticas sociais que não se deixam ler com facilidade. Não são necessárias leituras simples nem espaços transparentes, como são os espaços da gentrificação e dos condomínios fechados. À sua maneira, cada um desses cria isolamento e (auto)exclusão, embora à superfície prometa glamour, modernização e segurança. Por mais belas e perfeitas que possam ser as soluções arquitetônicas da gentrificação e dos condomínios fechados, em geral revelam-se ineficientes do ponto de vista do ordenamento urbanístico e danosas socialmente. Talvez tenhamos de enfrentar o desafio político do invisibilizado e do informal e tentar incorporar ambos nos planos formais de cidade e assegurar, assim, mais democraticidade ao nosso futuro urbano. Os planos de cidade dos arquitetos e urbanistas têm de reaprender com as cotidianidades igualmente difíceis de decifrar porque aparentemente irrepetíveis. São precisas rugosidades espaciais semelhantes às dificuldades da vida vivida no seu cotidiano e não leituras simplistas desses espaços. 


\section{Coda}

Ao escrever estas palavras vem-me à memória uma breve história contada pelo filósofo francês Valdimir Jankélévitch no seu livrinho L'irréversible et la nostalgie (Jankélévitch, 1974, pp. 52-53). De acordo com a sua narrativa, consta que, em 1851, Liev Tolstoï, então com apenas 23 anos de idade, lançou-se na escrita da História do dia de ontem, o que seria a sua primeira obra literária. $\mathrm{O}$ trabalho, porém, ficou inacabado porque, afinal, iria tratar de uma matéria monstruosa que não seria possível captar, dada a variedade e complexidade dos incontáveis detalhes de tantas ocorrências mínimas. Por isso, a maior parte dos acontecimentos de ontem seriam irrepetíveis e não comprováveis empiricamente, o que terá colocado Tolstoï perante a dificuldade insuperável de relatar as últimas 24 horas. O emaranhado difícil dos irrepetíveis eventos de ontem impedia a sua serena interpretação. Rendido a tal dificuldade, Tolstoï deixou inacabada o que seria a sua História do dia de ontem.

A falência do projeto ficou a dever-se, segundo Jankélévitch, ao convencimento de Tolstoï de que os acontecimentos de ontem são irrepetíveis e não demonstráveis. Mas, na verdade, a irreversibilidade não diz respeito a acontecimentos solenes e formais. São antes os acontecimentos insignificantes e informais que são realmente irrepetíveis. São esses acontecimentos leves e banais, os que realmente se renovam a cada dia. São esses que importa trazer para dentro dos desenhos formais de cidade, de modo a ensaiar alternativas de vida urbana que levem a sério o que parece insignificante por ter sido deliberadamente invisibilizado. Os "fazedores" da cidade do futuro não podem, como Tolstoï, desistir da sua obra, também difícil e complexa. Devem, isso sim, juntar-se à "esperança da sociologia” das cidades. 
Referências Bibliográficas

Amin, Ash \& Graham, Stephen. (1997), "The ordinary city”. Transactions of the Institute of British Geographers, 22 (4): 411-429.

Amin, Ash \& Thrift, Nigel. (2017), Seeing like a city. Londres, Polity.

Appadurai, Arjun. (2002), "Deep democracy: urban governmentality and the horizon of politics". Public Culture, 14(1): 1-47.

Aubert, Nicole \& Haroche, Claudine (orgs.). (2011), Les tyrannies de la visibilité. Etre visible pour exister? Paris, Éitionsèrés.

Benjamin, Walter. (2009), Passagens. Org. Willi Bolle. Belo Horizonte/São Paulo, UfmG/ Imprensa Oficial do Estado de São Paulo.

Benjamin, Walter \& Lacis, Asja. (1978), “Naples”. In: Benjamin, Walter. Reflections: essays, aphorisms, autobiographical writings. Org. Peter Demetz. Nova York/Londres, Harcourt Brace Jovanovich, pp. 163-173.

Bishop, Ryan, Phillips, John \& Yeo, Wey Wey (orgs.). (2003), Poscolonial urbanism: Southeastern Asian cities and global processes. Londres/Nova York, Routledge.

Cacciari, Massimo. (2010), La ciudad. Barcelona, Gustavo Gili.

CARTA, Maurizio. (2007), Creative city: dynamics, innovations and actions. Barcelona, LIst.

De Certeau, Michel. (1994), “Caminhadas pela Cidade”. In: De Certeau, Michel. A invenção do cotidiano. Vol. 1: Artes de fazer. Petrópolis, Vozes. pp. 157-177.

Diller, Elizabeth. (2018), “Contra o statu quo em arquitectura”. Ípsilon, 9 mar., pp. 4-9 (entrevista a Isabel Salema).

Fainstein, Susan. (2010), The just city. Ithaca, Cornell University Press.

Fernandes, Ana. (2006), "Cidades e cultura: Rompimento e promessa”. In: Jeudy, Henri-Pierre \& Jacques, Paola Berenstein (orgs.), Corpos e cenários urbanos. Salvador, Edufba, pp. 51-64.

FLORIDA, Richard. (2002), The rise of the creative class. Nova York, Basic Books.

FORTUNA, Carlos. (2016), “Velhas, novas e novíssimas narrativas do mundo urbano”. In: AMARO, António; Garrido, Álvaro \& Nunes, João (orgs.), Interdisciplinariedade e universidade. Coimbra, Imprensa da Universidade, pp. 95-109.

Fortuna, Carlos. (2018), "Caminhar urbano e vivências imprevistas". Revista Brasileira de Sociologia, 13 (6): 136-154.

Frehse, Fraya. (2017), “Da cidade ao corpo e vice-versa: Tempos e espaços”. Concurso de Livre-Docência. São Paulo, UsP. (mimeo).

Hall, Suzanne. (2012), City, street and citizen. The measure of the ordinary. Londres/Nova York, Routledge.

JacoBs, Jane. (2000), The death and life of great American cities. Londres, Pimlico.

JANkéLÉvitch, Valdimir. (1974), L'irréversible et la nostalgie. Paris, Flammarion. 
Latour, Bruno \& Hermant, Emilie. (1998), Paris ville invisible. Paris, La Découverte.

Lefebvre, Henri. (1980), La présence et l'absence. Paris, Casterman.

Lefebvre, Henri. (1991), The production of space. Oxford, Blackwell.

LeIte, Rogerio Proença. (2004), Contra-usos da cidade: lugares e espaço público na experiência urbana contemporânea. Campinas/Aracaju, Editora da Unicamp/Editora da UFs.

Leroi-Gourhan, André. (1964), Le geste et la parole. Paris, Bibliothèque Albin Michel, 2 vols.

LOFLAND, Lyn. (1998), The public realm: exploring the city's quintessential social territory. Nova York, Aldine de Gruyter.

Margali, Avishai. (1996), The decent society. Cambridge (Mass.), Harvard University Press.

Minton, Anna. (2009), Ground control: Fear and happiness in the twenty-first century city. Londres, Penguin Books.

Oldenburg, Ray. (1989), The great good place. Cambridge, Da Capo Press.

Pechman, Robert. (2014), "Desconstruindo a cidade. Cenários para a nova literatura urbana”. In: Kuster, Eliana \& Pechman, Robert. O chamado da cidade: ensaios sobre a urbanidade. Belo Horizonte, Editora da UFMG, pp. 89-102.

Ricoeur, Paul. (1991), Temps et récit. Paris, Seuil, 3 vols.

Robinson, Jennifer. (2006), Ordinary cities: between modernity and development. Londres/ Nova York, Routledge.

Roy, Ananya. (2009), "Strangely familiar: planning and the worlds of insurgence and informality". Planning Theory, 1 (8): 1-11.

Santos, Boaventura Sousa (2010), A gramática do tempo: para uma nova cultura politica. Porto, Afrontamento.

SEABROOK, Jeremy. (1996), The cities of the south: Scenes from a developing world. Londres, Verso.

Seabrook, Jeremy. (2007), Cities. Ann Arbor, Pluto Press.

SENNETT, Richard. (2108), Construir e habitar: ética para uma cidade aberta. Rio de Janeiro, Record.

Simone, Abdou Maliq. (2011), “The surfacing of urban life”. City, 3-4 (15): 355-64.

Sudjic, Deyan. (2017), The language of cities. Milton Keynes, Penguin Books.

Tonkiss, Fran. (2013), Cities by design: the social life of urban form. Cambridge, Polity.

TowsEnd, Anthony M. (2014), Smart cities: big data, civic hackers, and the quest for a new utopia. Nova York, Norton.

Wacquant, Loïc. (2008), As duas faces do gueto. São Paulo, Boitempo.

Watson, Sophie. (2006), City publics: the (dis)enchantments of urban encounters. Londres, Routledge.

Zukin, Sharon. (2010), Naked city: the death and life of authentic urban places. Oxford, Oxford University Press. 


\section{Resumo}

\section{Urbanidades invisíveis}

Apesar da apregoada visibilidade da cidade, a condição urbana encontra-se sujeita a níveis diferenciados de transparência. Muitas situações de invisibilidade e encobrimentos referem-se à informalidade do cotidiano, em especial nas margens e periferias da urbanidade. Ensaístico, o presente texto questiona a responsabilidade dos "fazedores" de cidade - arquitetos, urbanistas e decisores - no desprezo pelo lado informal de muitos espaços urbanos e da sua vida social. Há como planejar o informal da cidade? A possibilidade de uma cidade justa e aberta está condicionada, portanto, pela disponibilidade desses atores para uma abordagem mais próxima da realidade complexa que a sociologia e as ciências sociais vêm há muito a revelar e a tornar visível. Palavras-chave: Cidade; Invisibilidade; Informalidade urbana; Aceleracionismo urbano.

\section{Abstract}

\section{Invisible urbanities}

Despite the supposed visibility of the city, the urban condition remains submitted to different levels of transparency and blindness. Many invisibilities of the city refer to the informality of daily life, especially in the margins and peripheries of urbanity. Essayist in style, the text questions the responsibility of city "makers" - architects, urbanists and administrators - in this contempt for the informal side of many urban spaces and its social life. Can we plan the city's informality? A possible open city is conditioned by the availability of these actors to a closer approach to a complex reality that sociology and the social sciences have long been revealing and making visible. Keywords: City; Invisibility; Urban informality; Urban accelerationism.

Texto recebido em 19/10/2018 e aprovado em 7/11/2018.

DOI: $10.11606 / 0103-2070 . t s .2019 .151257$

CARLOS FORTUNa é sociólogo. Ph.D pela State University of New York (Binghamton). Professor na Faculdade de Economia da Universidade de Coimbra e Investigador no Centro de Estudos Sociais.E-mail: cfortuna@fe.uc.pt 